\title{
Partial Replacement of Fine Aggregates, Coarse Aggregates, Cement in Concrete
}

\author{
Akshay Chandel $^{1 *}$, Chandra Pal Gautam ${ }^{2}$ \\ ${ }^{1}$ Department of Civil Engineering, Himalayan Group of Professional Institutions, Kala Amb, India \\ ${ }^{2}$ Department of Civil Engineering, Jaypee University of Information Technology, Waknaghat, India
}

\begin{abstract}
Today, the need to protect environment is a moral obligation for human. The study investigates the suitability of using Crumb rubber as replacement of Fine aggregates, Waste Crushed tiles as Coarse aggregates and Bagasse as replacement of Cement. The results of the study revealed that the Compressive strength of the sample showed satisfactory performance. This experiment mainly deals with the manufacture of Concrete made from waste materials. The concrete cubes are tested under CTM for compressive strength. The cost comparison with the conventional concretes has revealed that Concrete made from these waste is preferred because it is more economical walling material in itself and permits the use of economical building techniques. Also by the use of concrete made from these wastes it allows the building to save its energy and Cost and enables the building to have a step forward towards Zero energy building and Economical also.
\end{abstract}

Keywords: Bagasse, Compressive strength, Crumb rubber, Waste crushed tiles.

\section{Introduction}

Waste materials become real concern for humans in today's life. The main issue is to decompose these materials, as these are responsible for environment pollution. Because of this problem this has becomes the point of interest for researcher across the world. Therefore, utilization of non-biodegradable waste material in construction is rapidly growing. It was observed that these waste materials can be unchanged on earth for hundreds of decade without degradation and this issue of disposal of non-biodegradable waste will not solve itself and certain practical steps have to be taken for solving this problem. The construction of structure is increasing day by day. Hence it's a time of increasing strength and stability of structures by utilizing waste material and reduces the overall cost of structures and pollution.

\section{A. Background Studies}

Several types of waste materials i.e. rice husk ash, recycle aggregate, fly ash, sewage sludge, waste glass sludge, marble powder, crumb rubber, electronic waste, hospital waste ash crumb rubber, waste crushed tile, bagasse and many more were used in concrete mix design by researcher across the world. It was observed that utilization of waste material as a partial replacement of materials in concrete results in mix which is eco- friendly, less cost and leads to sustainable construction.

\section{B. Benefits of Bagasse as Replacement of Cement}

Bagasse is the dry pulpy fibrous residue that remains after sugarcane or sorghum stalks are crushed to extract their juice. It is used as a bio fuel for the production of heat, energy, and electricity, and in the manufacture of pulp and building materials. It has very high silica content $(87 \%)$ than cement (22\%) which allow the concrete to be more durable and tough. Also it has very low specific gravity (1.8) than cement (3.14) which helps the concrete to become lighter. By using Bagasse as a partial replacement of cement we can reduce the landfill problems and leads to a sustainable construction.

\section{Benefits of Crumb Rubber as Replacement of Fine Aggregates}

Crumb rubber is recycled rubber produced from automotive and truck scrap tires. During the recycling process, steel and tire cord are removed, leaving tire rubber with a granular consistency. It improves the workability and thaw damage of concrete. It also provides sufficient restrain against propagation of micro-cracks. By using it as a replacement of fine aggregates we can solve the problem of its disposal in landfills as it is a very hazardous material. So by using Crumb rubber as a partial replacement of sand we can reduce the landfill problems and leads to a sustainable construction.

\section{Benefits of Waste Crushed Tiles as Replacement of Fine Aggregates}

Tiles in building construction are thin plates or elements used to cover surfaces like roofs, floors, and walls. Tiles have the capability to resist biological, chemical and physical degradation forces. These are so durable and hard that it can be used as a replacement of coarse aggregate in concrete so that we can solve the problem of its disposal. So by using using Waste tiles as a partial replacement of coarse aggregates we can reduce the landfill problems and leads to a sustainable construction.

\section{Materials and Properties}

\section{A. Cement}

Portland Pozzolana cement having 28days minimum 
Compressive strength of 33Mpa, (conforming to IS 1727: 1967) is used in this study as shown in fig 1. PPC cement is collected from local shop.

\section{B. Sand}

River sand locally available in the market was used in the investigation. In this study river sand of zone- 1 and zone- 2 is used as shown in fig. 2.

\section{Coarse Aggregates}

Crushed aggregates below $20 \mathrm{~mm}$ size produced from local crushing plants were used. The aggregate exclusively passing through $20 \mathrm{~mm}$ sieve size and retained on $10 \mathrm{~mm}$ sieve is selected as shown in fig. 3 .

\section{Bagasse}

Bagasse ash has a high amount of amorphous silicate and a broad specific surface area which makes it an effective pozzolanic additive to improve mechanical performance of the geo materials. In this study bagasse from Sandhar sugar mill Ltd. (Phagwara) as shown in fig. 4.

\section{E. Waste Crushed Tiles}

Broken mosaic tiles were collected from the solid waste of ceramic manufacturing unit and from demolished building. The waste tiles were crushed into small pieces by manually and by using crusher. The tile waste which is lesser than $4.75 \mathrm{~mm}$ size was neglected. The crushed tile aggregate passing through $16 \mathrm{~mm}$ sieve and retained on $12.5 \mathrm{~mm}$ sieve are used. In this study demolished tiles from nearby construction houses are collected as shown in fig. 5 .

\section{F. Crumb rubber}

Crumb rubber is recycled rubber produced from automotive and truck scrap tires. During the recycling process, steel and tire cord (fluff) are removed, leaving tire rubber with a granular consistency. Crumb rubber is collected from local tire remolding shop as shown in fig. 6 .

\section{G. Super plasticizer (SP)}

Super plasticizers (SP's) as shown in fig. 7. also known as high range water reducers, are additives used in making high strength concrete. The use of super plasticizers is practiced for production of flowing, self-compacting, and self-leveling and for the production of high strength and high performance concrete.

\section{H. Water}

Water plays a vital role in achieving the strength of concrete. For complete hydration it requires about 3/10th of its weight of water. Potable water fit for drinking is required to be used in the concrete and it should have $\mathrm{pH}$ value ranges between 6 to 9 .

\section{Methodology}

The methodology of research includes the collection of required materials from the various sources and determining the properties of all the materials gathered. Designing the concrete mix proportions for all types of replacements and Preparation of the concrete mix, Moulding and curing. The testing of concrete includes compressive strength of concrete in its hardened state at 7 and 28 days of curing. Testing results of 70 samples is shown in Table.1. In last the comparison of conventional \& Green concrete is done. The Combination of different waste material was used to replace the concrete component up to maximum percentage so that in table. 1 compressive strength of combination was represented in a form of 5B5C5T, which mean 5\% of Bagasse ash, 5\% of Crumb rubber and 5\% of Tiles were used to make cubes. From fig. 8 it can be clearly seen that $23 \%$ replacement gives the maximum strength.

Table 1

Variation in compressive strength of combinations of waste materials

\begin{tabular}{|c|c|c|c|c|c|}
\hline $\begin{array}{c}\text { Combination } \\
\%\end{array}$ & $\begin{array}{c}\text { Mix } \\
\text { no. }\end{array}$ & $\begin{array}{c}\text { Casting } \\
\text { - I }\end{array}$ & $\begin{array}{c}\text { Casting } \\
\text { - II }\end{array}$ & $\begin{array}{c}\text { Casting - } \\
\text { III }\end{array}$ & $\begin{array}{c}\text { Average } \\
\text { MPa }\end{array}$ \\
\hline 0B0C0T & M0 & 42.65 & 46.87 & 44.62 & 44.71 \\
\hline 0B1C0T & M1 & 45.58 & 43.80 & 47.90 & 45.76 \\
\hline 0B1C5T & M2 & 41.77 & 42.63 & 40.25 & 41.55 \\
\hline 0B1C10T & M3 & 39.72 & 41.62 & 40.01 & 40.45 \\
\hline 0B1C15T & M4 & 40.90 & 45.15 & 43.42 & 43.15 \\
\hline 0B1C20T & M5 & 42.56 & 45.37 & 46.32 & 44.75 \\
\hline 0B2C0T & M6 & 43.65 & 44.87 & 44.62 & 44.38 \\
\hline 0B2C5T & M7 & 43.91 & 44.52 & 45.31 & 44.58 \\
\hline 0B2C10T & M8 & 40.20 & 41.12 & 39.90 & 40.40 \\
\hline 0B2C15T & M9 & 46.20 & 42.18 & 43.34 & 43.96 \\
\hline 0B2C20T & M10 & 43.80 & 42.34 & 45.80 & 43.98 \\
\hline 0B3C0T & M11 & 38.48 & 40.37 & 42.36 & 40.40 \\
\hline 0B3C5T & M12 & 39.59 & 41.73 & 40.28 & 40.53 \\
\hline 0B3C10T & M13 & 43.59 & 40.79 & 41.37 & 41.96 \\
\hline 0B3C15T & M14 & 43.72 & 43.59 & 42.89 & 43.40 \\
\hline 0B3C20T & M15 & 44.72 & 42.51 & 41.53 & 42.92 \\
\hline $5 \mathrm{~B} 0 \mathrm{C} 0 \mathrm{~T}$ & M16 & 41.64 & 40.96 & 42.65 & 41.75 \\
\hline $5 \mathrm{~B} 1 \mathrm{C} 0 \mathrm{~T}$ & M17 & 42.74 & 43.01 & 41.77 & 42.50 \\
\hline $5 \mathrm{~B} 1 \mathrm{C} 5 \mathrm{~T}$ & M18 & 39.90 & 38.62 & 40.15 & 39.55 \\
\hline 5B1C10T & M19 & 40.77 & 38.91 & 37.65 & 39.11 \\
\hline 5B1C15T & M20 & 44.90 & 45.15 & 44.42 & 44.82 \\
\hline $5 \mathrm{~B} 1 \mathrm{C} 20 \mathrm{~T}$ & M21 & 44.56 & 45.37 & 45.32 & 44.71 \\
\hline $5 \mathrm{~B} 2 \mathrm{C} 0 \mathrm{~T}$ & M22 & 43.75 & 44.87 & 44.62 & 44.41 \\
\hline $5 \mathrm{~B} 2 \mathrm{C} 5 \mathrm{~T}$ & M23 & 43.81 & 44.32 & 45.11 & 44.41 \\
\hline $5 \mathrm{~B} 2 \mathrm{C} 10 \mathrm{~T}$ & M24 & 40.36 & 40.12 & 39.80 & 40.09 \\
\hline $5 \mathrm{~B} 2 \mathrm{C} 15 \mathrm{~T}$ & M25 & 44.20 & 43.98 & 44.64 & 44.27 \\
\hline $5 \mathrm{~B} 2 \mathrm{C} 20 \mathrm{~T}$ & M26 & 43.80 & 42.74 & 44.80 & 43.78 \\
\hline $5 \mathrm{~B} 3 \mathrm{C} 0 \mathrm{~T}$ & M27 & 40.48 & 40.37 & 41.36 & 40.73 \\
\hline $5 \mathrm{~B} 3 \mathrm{C} 5 \mathrm{~T}$ & M28 & 40.59 & 40.73 & 41.28 & 40.86 \\
\hline 5B3C10T & M29 & 40.59 & 40.79 & 41.37 & 40.91 \\
\hline 5B3C15T & M30 & 43.72 & 43.59 & 42.89 & 43.40 \\
\hline $5 \mathrm{~B} 3 \mathrm{C} 20 \mathrm{~T}$ & M31 & 43.90 & 44.15 & 44.42 & 44.15 \\
\hline 10B0C0T & M32 & 44.56 & 45.27 & 45.22 & 45.01 \\
\hline 10B1C0T & M33 & 43.65 & 44.77 & 44.22 & 44.21 \\
\hline 10B1C5T & M34 & 43.71 & 44.34 & 44.11 & 44.05 \\
\hline 10B1C10T & M35 & 40.26 & 40.02 & 39.70 & 39.99 \\
\hline 10B1C15T & M36 & 44.10 & 43.88 & 44.24 & 44.07 \\
\hline 10B1C20T & M37 & 43.57 & 43.74 & 44.70 & 44.00 \\
\hline 10B2C0T & M38 & 40.38 & 40.74 & 41.26 & 40.79 \\
\hline 10B2C5T & M39 & 40.29 & 40.63 & 41.48 & 40.8 \\
\hline 10B2C10T & M40 & 40.46 & 40.67 & 41.46 & 40.86 \\
\hline 10B2C15T & M41 & 42.46 & 43.37 & 43.32 & 43.05 \\
\hline 10B2C20T & M42 & 43.85 & 44.17 & 44.32 & 44.11 \\
\hline 10B3C0T & M43 & 43.91 & 44.22 & 44.31 & 44.14 \\
\hline 10B3C5T & M44 & 40.10 & 41.02 & 39.90 & 40.34 \\
\hline 10B3C10T & M45 & 46.20 & 42.18 & 43.34 & 43.90 \\
\hline 10B3C15T & M46 & 43.90 & 43.64 & 44.80 & 44.11 \\
\hline 10B1C10T & M35 & 40.26 & 40.02 & 39.70 & 39.99 \\
\hline 10B1C15T & M36 & 44.10 & 43.88 & 44.24 & 44.07 \\
\hline 10B1C20T & M37 & 43.57 & 43.74 & 44.70 & 44.00 \\
\hline 10B2C0T & M38 & 40.38 & 40.74 & 41.26 & 40.79 \\
\hline 10B2C5T & M39 & 40.29 & 40.63 & 41.48 & 40.8 \\
\hline
\end{tabular}




\begin{tabular}{|l|l|l|l|l|l|}
\hline 10B2C10T & M40 & 40.46 & 40.67 & 41.46 & 40.86 \\
\hline 10B2C15T & M41 & 42.46 & 43.37 & 43.32 & 43.05 \\
\hline 10B2C20T & M42 & 43.85 & 44.17 & 44.32 & 44.11 \\
\hline 10B3C0T & M43 & 43.91 & 44.22 & 44.31 & 44.14 \\
\hline 10B3C5T & M44 & 40.10 & 41.02 & 39.90 & 40.34 \\
\hline 10B3C10T & M45 & 46.20 & 42.18 & 43.34 & 43.90 \\
\hline 10B3C15T & M46 & 43.90 & 43.64 & 44.80 & 44.11 \\
\hline 10B3C20T & M47 & 41.08 & 41.67 & 42.26 & 41.67 \\
\hline 15B0C0T & M48 & 39.59 & 40.73 & 40.28 & 40.2 \\
\hline 15B1C0T & M49 & 41.59 & 40.69 & 41.27 & 41.18 \\
\hline 15B1C5T & M50 & 42.72 & 43.29 & 42.69 & 42.9 \\
\hline 15B1C10T & M51 & 43.72 & 43.51 & 42.93 & 43.38 \\
\hline 15B1C15T & M52 & 41.84 & 41.66 & 42.55 & 42.01 \\
\hline 15B1C20T & M53 & 42.74 & 43.31 & 43.77 & 43.27 \\
\hline 15B2C0T & M54 & 40.58 & 40.64 & 41.16 & 40.79 \\
\hline 15B2C5T & M55 & 40.92 & 40.73 & 41.38 & 41.01 \\
\hline 15B2C10T & M56 & 40.36 & 40.57 & 41.36 & 40.76 \\
\hline 15B2C15T & M57 & 46.31 & 45.23 & 47.98 & 46.50 \\
\hline 15B2C20T & M58 & 43.72 & 43.59 & 42.89 & 43.40 \\
\hline 15B3C0T & M59 & 43.90 & 44.45 & 44.42 & 44.15 \\
\hline 15B3C5T & M60 & 44.56 & 45.27 & 45.22 & 45.01 \\
\hline 15B3C10T & M61 & 43.65 & 44.77 & 44.22 & 44.21 \\
\hline 15B3C15T & M62 & 43.71 & 44.34 & 44.11 & 44.05 \\
\hline 15B3C20T & M63 & 40.26 & 40.02 & 39.70 & 39.99 \\
\hline 20B0C0T & M64 & 44.10 & 43.88 & 44.24 & 44.07 \\
\hline 20B1C0T & M65 & 43.57 & 43.74 & 44.70 & 44.00 \\
\hline 20B1C5T & M66 & 40.38 & 40.74 & 41.26 & 40.79 \\
\hline 20B1C10T & M67 & 40.29 & 40.63 & 41.48 & 40.8 \\
\hline 20B1C15T & M68 & 40.46 & 40.67 & 41.46 & 40.86 \\
\hline 20B1C20T & M69 & 42.46 & 43.37 & 43.32 & 43.05 \\
\hline 20B2C0T & M70 & 43.85 & 44.17 & 44.32 & 44.11 \\
\hline
\end{tabular}

Table 2

Comparison of costs for conventional and green concrete for $1 \mathrm{~m}^{3}$ (excluding deduction of windows, doors etc.)

\begin{tabular}{|l|c|c|}
\hline \multicolumn{1}{|c|}{ Materials } & $\begin{array}{c}\text { Cost of } \\
\text { Conventional } \\
\text { concrete (Rupees) }\end{array}$ & $\begin{array}{c}\text { Cost of Green } \\
\text { concrete (Rupees) }\end{array}$ \\
\hline Cement & 2800 & 2512 \\
\hline Coarse aggregates & 812 & 1052 \\
\hline Fine aggregates & 893 & 902 \\
\hline Total cost & 4505 & 4466 \\
\hline
\end{tabular}

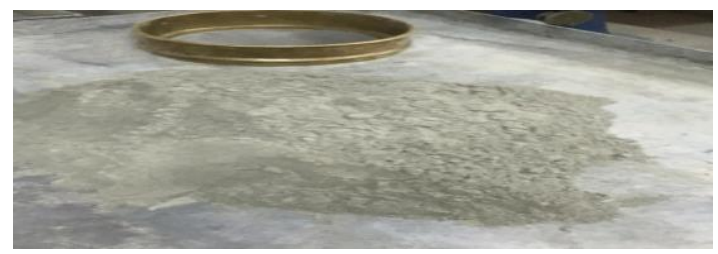

Fig. 1. Portland Pozolana Cement used at lab

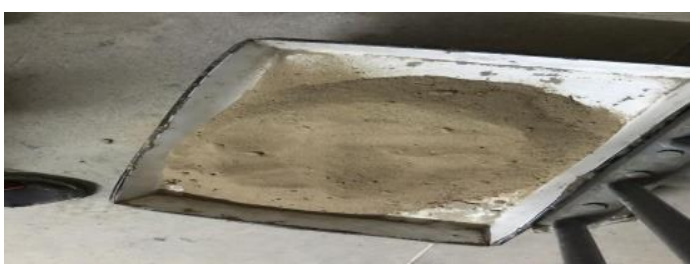

Fig. 2. Sand used for design mix

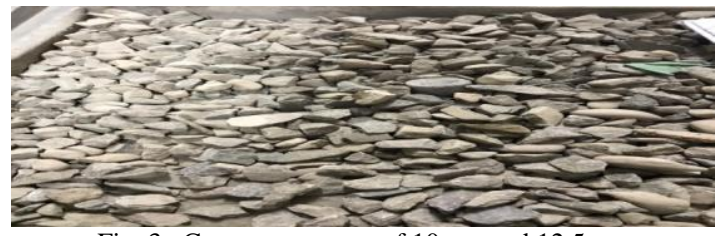

Fig. 3. Coarse aggregate of $10 \mathrm{~mm}$ and $12.5 \mathrm{~mm}$

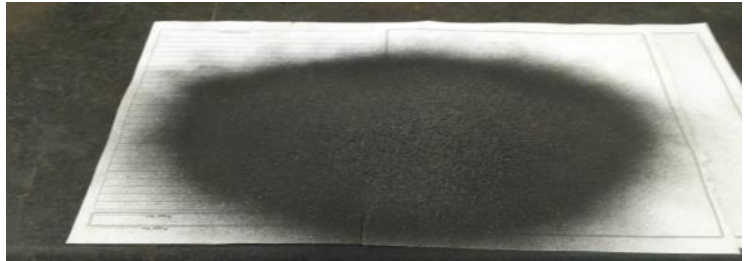

Fig. 4. Bagasse used as replacement of cement

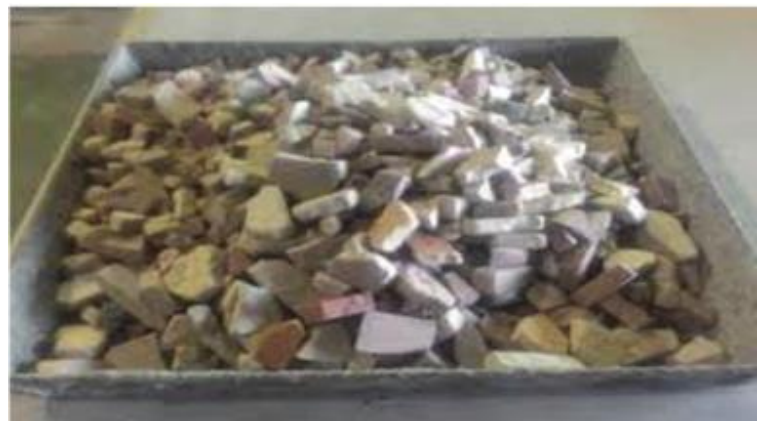

Fig. 5. Waste crushed tiles used as replacement of CA

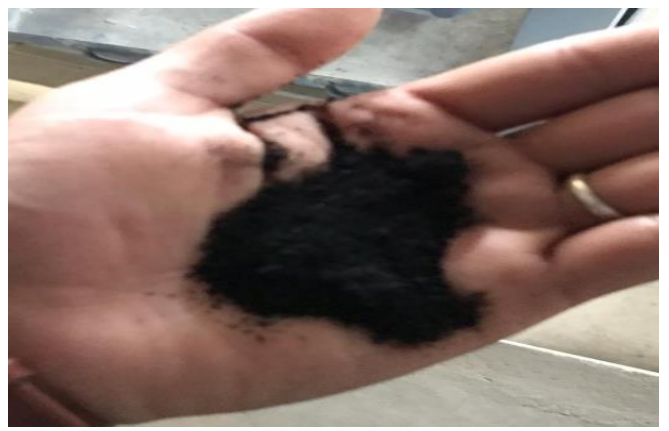

Fig. 6. Crumb rubber used as replacement of FA

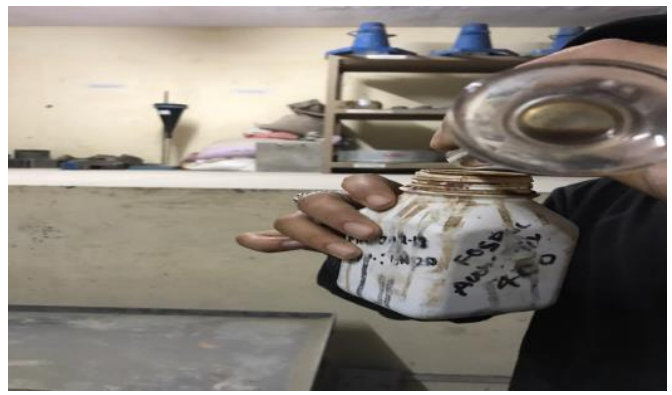

Fig. 7. Super plasticizer used in design mix

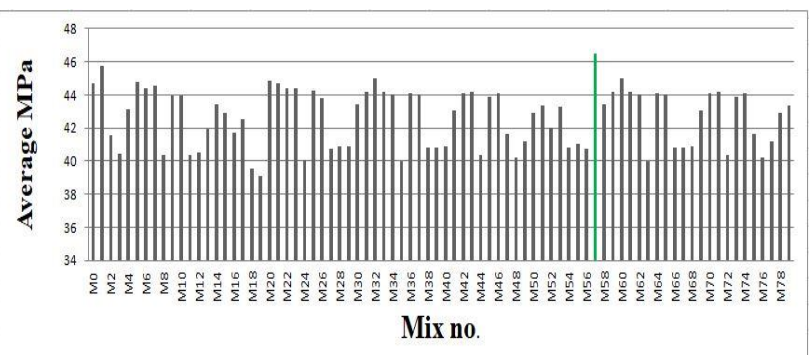

Fig. 8. Graph between compressive strength and combination $\%$ of waste material

\section{Conclusion}

From the test results and codal provisions, the following conclusions were drawn,

1. Compressive strength increases with increase in 
percentage of bagasse up to $15 \%$ after that it starts decreasing.

2. Compressive strength increases with increase in percentage of crumb rubber up to $2 \%$ after that it starts decreasing.

3. Compressive strength increases with increase in percentage of waste crushed tiles up to $15 \%$ after that it starts decreasing.

4. Cost of Green concrete increased up to some extent but for long term it turns out to be beneficial and economical also.

\section{References}

[1] A. Assadollahi and C. Moore, "Effects of Crumb Rubber on Concrete Properties When Used as an Aggregate in Concrete Mix Design," in Structures Congress, pp. 308-314, 2017

[2] M. Elchalakani, H. Basarir, and A. Karrech, "Green concrete with highvolume fly ash and slag with recycled aggregate and recycled water to build future sustainable cities," in Journal of Materials in Civil Engineering, vol. 29, no. 2, p. 04016219, 2016.

[3] M. A. Danish and D. L. Budhlani, "Review on Partial Replacement of Course and Fine Aggregate by Mossiac Tile Chips and Granite Powder".

[4] S. A. Memon, M. A. Sheikh, and M. B. Paracha, "Utilization of hospital waste ash in concrete," in Mehran University Research Journal of Engineering \& Technology, vol. 32, no. 1, 2013. 